\title{
Planta
}

\section{The dominant allele Aft induces a shift from flavonol to anthocyanin production in response to UV-B radiation in tomato fruit. \\ --Manuscript Draft--}

\begin{tabular}{|c|c|c|}
\hline Manuscript Number: & \multicolumn{2}{|l|}{ PLAA-D-17-00169R1 } \\
\hline Full Title: & \multicolumn{2}{|c|}{$\begin{array}{l}\text { The dominant allele Aft induces a shift from flavonol to anthocyanin production in } \\
\text { response to UV-B radiation in tomato fruit. }\end{array}$} \\
\hline Article Type: & \multicolumn{2}{|c|}{ S.I. : Polyphenols 2016} \\
\hline Corresponding Author: & \multicolumn{2}{|c|}{$\begin{array}{l}\text { Antonella Castagna, Ph.D. } \\
\text { Universita degli Studi di Pisa } \\
\text { ITALY }\end{array}$} \\
\hline \multicolumn{3}{|l|}{$\begin{array}{l}\text { Corresponding Author Secondary } \\
\text { Information: }\end{array}$} \\
\hline Corresponding Author's Institution: & \multicolumn{2}{|c|}{ Universita degli Studi di Pisa } \\
\hline \multicolumn{3}{|l|}{$\begin{array}{l}\text { Corresponding Author's Secondary } \\
\text { Institution: }\end{array}$} \\
\hline First Author: & \multicolumn{2}{|l|}{ Stefano Catola } \\
\hline \multicolumn{3}{|l|}{ First Author Secondary Information: } \\
\hline \multirow[t]{7}{*}{ Order of Authors: } & \multicolumn{2}{|l|}{ Stefano Catola } \\
\hline & \multicolumn{2}{|c|}{ Antonella Castagna, Ph.D. } \\
\hline & \multicolumn{2}{|l|}{ Marco Santin } \\
\hline & \multicolumn{2}{|l|}{ Valentina Calvenzani } \\
\hline & \multicolumn{2}{|l|}{ Katia Petroni } \\
\hline & \multicolumn{2}{|l|}{ Andrea Mazzucato } \\
\hline & \multicolumn{2}{|l|}{ Annamaria Ranieri } \\
\hline \multicolumn{3}{|c|}{ Order of Authors Secondary Information: } \\
\hline \multirow[t]{2}{*}{ Funding Information: } & University of Pisa & Not applicable \\
\hline & University of Milan & Not applicable \\
\hline Abstract: & \multicolumn{2}{|c|}{$\begin{array}{l}\text { Introgression of the dominant allele Anthocyanin fruit (Aft) from Solanum chilense } \\
\text { induces anthocyanin accumulation in the peel of tomato (Solanum lycopersicum L.) } \\
\text { fruit. UV-B radiation can influence plant secondary metabolism regulating the } \\
\text { expression of several genes, among which those involved in flavonoid biosynthesis. } \\
\text { Here, we investigated whether post-harvest UV-B treatment could up-regulate } \\
\text { flavonoid production in tomato fruits and whether the Aft allele could affect flavonoid } \\
\text { biosynthesis under UV-B radiation. } \\
\text { Mature green fruits of an anthocyanin-rich tomato mutant line (SA206) and of its wild } \\
\text { type reference, cv. Roma, were daily subjected to post-harvest UV-B treatment until full } \\
\text { ripening. } \\
\text { Up-regulation of CHS and CHI transcription by UV-B treatment induced flavonoid } \\
\text { accumulation in the peel of cv. Roma. Conversely, UV-B decreased the total flavonoid } \\
\text { content and CHS transcript levels in the SA206 peel. Being SA206 a double mutant } \\
\text { containing also hp-1 allele, we investigated also the behaviour of hp-1 fruit. The } \\
\text { decreased peel flavonoid accumulation and gene transcription in response to UV-B } \\
\text { suggest that hp-1 allele is involved in the marked down-regulation of the flavonoid } \\
\text { biosynthesis observed in SA206 fruit. Interestingly, in SA206, UV-B radiation promoted } \\
\text { the synthesis of delphinidin, petunidin, and malvidin by increasing F3'5'H and DFR } \\
\text { transcription, but it decreased rutin production, suggesting a switch from flavonols to } \\
\text { anthocyanins. Finally, although UV-B radiation does not reach the inner fruit tissues, it } \\
\text { down-regulated flavonoid biosynthesis in the flesh of both genotypes. }\end{array}$} \\
\hline
\end{tabular}


This study provides, for the first time, evidence that the presence of the functional Aft allele, under UV-B radiation, redirects flavonoid synthesis towards anthocyanin production and suggests that the hp-1 allele negatively influences the response of flavonoid biosynthesis to UV-B. 
Ref.: Ms. No. PLAA-D-17-00169

The dominant allele Aft induces a shift from flavonol to anthocyanin production in response to UV$B$ radiation in tomato fruit.

Planta

Dear Dr. Shrikanth,

We are grateful to the reviewers for their useful comments and suggestions.

Please find below our reply to any point raised.

Kind regards

Antonella Castagna 
Reviewers' comments:

Reviewer \#2: This generally well-written manuscript provides interesting and potentially useful data on the levels of flavonoids and flavonoid-biosynthesis transcripts in tomato fruit after UV-B radiation. The authors conclude that the capacity to synthesise anthocyanins in the tomato fruit is associated with a reduction in the capacity for the synthesis of colourless flavonoids to be upregulated in response to UV-B. The authors used apposite contemporary methodology, they appropriately analysed and presented the data, and their conclusions seem compelling in the light of their evidence. I have only a few minor points that the authors may wish to consider in their revision of this manuscript.

P6 line 56: It is not really obvious to the reader why this work was done. I suggest that they build a stronger justification for the work (e.g. indicating where the gaps in our knowledge are), leading to an explicit statement of the hypothesis they are testing.

A short paragraph was added before the aim of the paper to introduce and better clarify the reasons of our research: "Genetic manipulation or traditional breeding are useful approaches to induce anthocyanin production in tomato fruit, which could be further stimulated by choosing the most adequate light environment. Synthesis of anthocyanins, as well as of other flavonoids, is in fact strictly controlled by light intensity and quality, in particular by UV-B radiation. However, at the best of our knowledge, no information is available on the $U V-B$ influence on anthocyanin synthesis in tomato fruit. To unravel whether the effect of $U V-B$ radiation on flavonoid biosynthesis was influenced by the presence of the dominant allele Aft...."

P7 line 10: I would remove this last sentence, which is a summary of the key results, from the introduction.

Following the reviewer' suggestion the sentence was removed

P8 line 34: Were all 18 fruits selected from different plants? Were they located at the same nodes on different plants, and at comparable positions within the tomato trusses? If not, is it not possible that the reported differences in flavonoid levels might have resulted from positional effects? Also, why pool the data; wouldn't the composition of individual fruits have provided greater statistical strength?

- Fruits were collected from different plants, placed randomly inside the tunnel and sufficiently distant to ensure the most homogeneous light. Healthy fruits of comparable dimension were carefully harvested from second-third sunny branches (this information was added to the revised manuscript).

- We agree that composition of individual fruits would provide greater statistical strength but it requires analysing a considerable number of individual fruits to be representative. Moreover, peel taken from a single fruit was not sufficient to carry on both biochemical and molecular analyses. Therefore, we decided to balance the need to have independent samples with the necessity to collect sufficient material by pooling together some individual fruits and considering such a pool the biological replicate.

P11 line 37: Wouldn't the 'dilution effect' have been avoided if the data were expressed as per unit dry weight rather than fresh weight? 
Undoubtedly flesh contains much more water than peel, but differences in phenolic concentration between the two tissues are evident also when data are reported on dry weight basis. For example, peel and flesh of SA206control fruits contains about 622 and $37 \mathrm{mg} / 100 \mathrm{~g}$ fw (ratio peel/flesh being 16.8). When data are expressed on dry weight basis concentrations are 22.2 and $5.6 \mathrm{mg} / \mathrm{g} d w$ phenols, respectively, with ratio peel/flesh $=3.95$.

The same is true for Roma control fruit, that contains 236 and $47 \mathrm{mg} / 100 \mathrm{~g} f \mathrm{w}$ in peel and flesh, respectively (ratio peel/flesh being 5), while, when reported on dry weight basis, values are 16.5 and $7.12 \mathrm{mg} / \mathrm{g} d \mathrm{w}$ phenols (ratio peel/flesh $=2.32$ ).

Therefore, even if differences between the two tissues are reduced by expressing data on a dry weight basis, they are not suppressed. A short comment on this behaviour was added in the revised discussion.

P17 line 54: The effects of UV are seen in regions of the fruit that don't receive UV. This has been observed previously in other fruit species (e.g. kiwifruit). Perhaps the authors might like to give a little more information on the possible" signal transduction pathway" to which they elude?

Diffusible signals could be involved in transferring information from peel to flesh.

Ethylene plays a pivotal role during tomato ripening and we previously found that its emission is depressed in fruits ripened under UV-B shielding conditions. In that study, the use of tomato mutants allowed us to establish that carotenoid synthesis is influenced by UV-B though ethylenedependent and ethylene-independent mechanisms (Becatti et al. 2009).

Application of gibberellic acid was shown to up-regulate CHI and other phenylpropanoid biosynthetic genes (Cheng et al. BMC Genomics (2015) 16:128).

In a very recent paper, Bernula and co-workers $(2017$ Plant Cell Environment doi: 10.1111/pce.12904) state that "we found no evidence at the molecular level that UVR8signalling initiates signal crosstalk between different tissues. However, it was reported that UV$B$ irradiation of certain parts of the plants results in changes of gene expression in shielded organs, indicating that $U V$-B-induced inter-organ signalling can occur in higher plants (Casati $\&$ Walbot, 2004). Therefore, we hypothesize that inter-tissue signalling, mediated by yet unknown mobile compounds, contributes to the manifestation of UVR8-regulated responses. For example, it was reported that HY5 regulates auxin signalling under different light treatments including UV-B irradiation (Cluis et al., 2004; Sibout et al., 2006; Hayes et al., 2014; Vandenbussche et al., 2014). However, to unravel the molecular aspects of UVR8-modulated hormone signalling requires the development of new cellular markers."

Similarly, in our research, in the absence of specifically targeted study, we can only speculate on the possible signals that mediate flavonoid synthesis in the flesh in response to UV-B.

Accordingly, we prefer to avoid reference to a specific signal and we added only the generic sentence: "Specifically targeted studies are needed to elucidate the nature of signals that mediate flavonoid synthesis in response to UV-B in the flesh."

P15 paragraph 3: In my opinion, one of the most intriguing features of the data has been overlooked from this discussion. The transcript levels of CHS, CHI, F3H and F3'H are all lower in SA206 peels than in Roma peels, and are further attenuated in SA206 after irradiation with UVB. Presumably, then, the levels of dihydrokaempferol would be lower in SA206 than in Roma, and even lower following irradiation. Since dihydrokaempferol is the essential substrate for DFR, ANS, and UFGT activities, wouldn't we expect lower concentrations of anthocyanins after UV, rather than higher? I think that this observation can be explained, and it should be discussed here.

The lower transcription of the genes upstream dihydrokaempferol in UVB-treated peel of SA206 fruits leads to a lower total flavonoid concentration. The finding of an increased anthocyanin production, supported by the enhanced F3'5'H and DFR expression level, suggests that dihydrokaempferol is preferentially converted to dihydroquercetin and then dihydromyricetin which is then used to drive the synthesis of anthocyanins rather than flavonols. It is known that 
in Solanaceous species, the DFR enzyme is specific for dihydromyricetin and does not accept dihydrokaempferol as a substrate (Bovy et al, Plant Cell 14:2509-2526). Furthermore, it should be noted that the anthocyanin amount is very low as compared to total flavonoids, and accordingly, it does not alter the general trend to decrease shown by total flavonoids. A comment on this was added in the revised manuscript: "The lower transcription of $F 3 H$ and F3'H in SA206 peel after irradiation with UV-B suggests that levels of dihydroflavonols would be lower as well and a minor concentration of anthocyanins would be expected. Interestingly, $U V-B$ radiation instead led to increased anthocyanin synthesis, while decreasing flavonol production, suggesting that UV-B radiation by enhancing F3'5' $H$ promotes the conversion of dihydrokaempferol to dihydromyricetin, which is then specifically used by the tomato DFR enzyme to drive the synthesis of anthocyanins. In Solanaceous species, the DFR enzyme is in fact specific for dihydromyricetin and does not accept dihydrokaempferol as a substrate (Bovy et al. 2002)" 
Reviewer \#3: The manuscript entitled 'The dominant allele Aft induces a shift from flavonol to anthocyanin production in response to UV-B radiation in tomato fruit' by Catola et al describes the effects of two previously identified loci on the amounts of various flavonoids in the peel and flesh of tomato fruits following UV treatment. Major findings were that Aft increased anthocyanin accumulation in response to UV in the peel whereas hp- 1 decreased flavonoid accumulation in this tissue. The manuscript should be considered for publication in Planta after addressing only minor issues.

\begin{abstract}
:
was confusing because the authors state that SA206 mutant had decreased flavonoid accumulation but then state that it had increased anthocyanin accumulation. While it is possible to have both, anthocyanins are a type of flavonoid and the abstract would benefit from clarification that 'flavonoids' refers to total flavonols and anthocyanins.

The Abstract was revised adding the word "total" before flavonoid (line 38 of the old manuscript), and changing the word "anthocyanin" with "delphinidin, petunidin, and malvidin" and "flavonol" with "rutin" (lines 50-52, old manuscript) as follows: ".. in SA206, UV-B radiation promoted the synthesis of delphinidin, petunidin, and malvidin by increasing F3' 5' $\mathrm{H}$ and DFR transcription, but it decreased rutin production...".

Moreover, in the first sentence of the revised introduction, we inserted that anthocyanins are a class of flavonoids.
\end{abstract}

\title{
Introduction:
}

The comment 'Pollinators attraction... are the most important functions of anthocyanins in plants' should be stated less strongly since the role of anthocyanins in all of these functions has not been firmly established and is still a question of ongoing research. Further, the role of anthocyanins in defense against UV-B solar radiation damage is highly questionable since anthocyanins absorb much less UV compared to flavonols and are likely to act as antioxidants in that respect. Following the reviewer' suggestion, the statement was made less direct: "Pollinators attraction ... have been proposed as important functions of anthocyanins in plants"

\section{Methods:}

Since flavonoids are polyphenols, it should be clarified what exactly is being measured by the Folin-Ciocalteau colorimetric method.

Likewise, I looked in Kim et al. (2003), and the article it cited, to determine how total flavonoids were being measured. I didn't find information indicating exactly what compounds this method is measuring. Is it measuring flavonoids exclusively and not polyphenols?

Specify more clearly how each of these methods works and what they measure.

The chemical reactions at the basis of the two assays are quite different. Folin-Ciocalteau assay, which is used to measure total phenolics, is based on phenol oxidation by two strong inorganic oxidants (phosphotungstic and phosphomolibdic acids) in alkaline medium.

The aluminium chloride (AlCl3) colorimetric method is based on the metal-chelating property of flavonoids. The complex formation is carried out in the presence of NaNO2 and is based on the nitration of any aromatic ring with hydroxyl groups at three or four positions unsubstituted or not sterically blocked. After addition of AlCl3, a (yellow) complex is formed which immediately after $\mathrm{NaOH}$ addition becomes red.

A short explanation of the chemical basis of the two assays was added in the revised manuscript.

\section{Results section:}




\section{Discussion section:}

The paragraph beginning with 'Downstream naringenin' should be corrected to state 'Downstream from naringenin'.

The sentence was corrected following the reviewer's comment.

The discussion would benefit from explaining more about how UV regulation of flavonoids occurs in the model plant Arabidopsis, and how Aft and hp- 1 are suspected to fit into the mechanism if at all.

- Following the reviewer' suggestion, a paragraph on the mechanism of UV-B regulation of flavonoid synthesis in Arabidopsis was added: "In the model plant Arabidopsis the flavonoid pathway is activated by two different sets of transcription factors, controlling the early (i.e. AtMYB11/12/111) or the late (i.e. the MYB-bHLH-WD40 complex) biosynthetic genes (Petroni and Tonelli, 2011; Stracke et al., 2010). The major effector of UVR8-mediated gene expression is the ELONGATED HYPOCOTYL 5 (HY5) transcription factor, that controls many of the downstream target genes, among which MYB12 (Stracke et al., 2010), the negative regulator of phenylpropanoids MYB4 (Hemm et al. 2001), and PAP1, one of four R2R3 MYB activators involved in anthocyanin biosynthesis (Shin et al. 2013)",

- A short paragraph on the role played and hp-1 was introduced as reported below:

"Tomato plants carrying hpl mutation are characterized by exaggerated light responsiveness and photomorphogenic response. HP1 gene encodes the tomato homologue of DDB1, a light signal transduction proteins that in Arabidopsis participates to the formation of the complex CUL4DDB1-COP1-SPA, a CUL4-DDB1-based E3 ubiquitin ligases that suppresses the photomorphogenic program by targeting the transcription factor HY5 for degradation (Huang et al., 2013). In tomato, HP1/SIDDB1 is an essential component of CUL4-based E3 ligase complex (Wang et al., 2008). Since under UV-B radiation, UVR8 monomer sequesters COP1 from DDB1, causing physical dissociation and consequent loss of function of the complex, a role for $H P 1 / S I D D B 1$ in the response to $U V-B$ radiation cannot be excluded."

- A possible involvement of Aft in the mechanism of UV-B control of flavonoid synthesis cannot be excluded, being Aft a transcription factors belonging to the R2R3-MYB family just like MYB12, known to be transcribed under the control of the UVR8-mediated HY5 transcription factor. A short sentence on this possibility was added in the revised discussion: "In the light of the possible role of the Aft gene product as a transcription factors belonging to the R2R3-MYB family (Schreiber et al. 2012; Boches and Myers 2007), an involvement of Aft in the mechanism of UV-B control of flavonoid synthesis cannot be excluded. MYB12, a member of the R2R3-MYB family, is in fact known to be transcribed under the control of the UVR8-mediated HY5 transcription factor (Stracke et al. 2010)." 


\section{$\underline{\text { Original Article }}$}

The dominant allele Aft induces a shift from flavonol to anthocyanin production in response to $\mathrm{UV}-\mathrm{B}$ radiation in tomato fruit

Stefano Catola ${ }^{1}$, Antonella Castagna ${ }^{2 *}$, Marco Santin $^{2}$, Valentina Calvenzani ${ }^{3}$, Katia Petroni $^{3 * *}$, Andrea Mazzucato ${ }^{4}$, Annamaria Ranieri ${ }^{2,5}$

${ }^{1}$ Trees and Timber Institute IVALSA, National Research Council of Italy, Via Madonna del Piano 10, 50019 Sesto Fiorentino (FI), Italy

${ }^{2}$ Department of Agriculture, Food and Environment, University of Pisa, via del Borghetto 80, 56124 Pisa, Italy

${ }^{3}$ Department of BioSciences, University of Milan, Via Celoria 26, 20133 Milan, Italy

${ }^{4}$ Department of Agricultural and Forestry Sciences, University of Tuscia, Via S. C. de Lellis, 01100 Viterbo, Italy

${ }^{5}$ Interdepartmental Research Center Nutrafood "Nutraceuticals and Food for Health", University of Pisa, via del Borghetto 80, 56124 Pisa, Italy

* Corresponding author: Antonella Castagna

e-mail: antonella.castagna@ unipi.it; phone: +39 (0)50 2216608; fax: +39 (0)50 2220606.

** Co-corresponding author: Katia Petroni

Email: katia.petroni@unimi.it; phone: +39 0250315010; fax: +39 0250315044

\section{Author contribution statement}


AR and KP conceived and designed research. SC, AC, MS and VC conducted experiments. AC, AM and VC analyzed data. AC, AM and KP wrote the manuscript. All authors read and approved the manuscript

\section{Acknowledgments}

The research was supported by funds of the University of Pisa and the University of Milan. We are indebted with Prof. Gian Piero Soressi (University of Tuscia) for sharing genetic material and Prof. Chiara Tonelli (University of Milan) for helpful discussions. We kindly acknowledge Prof. Åke Strid (School of Science \& Technology, Orebro University) for measurement of light transmittance across tomato peel. 


\begin{abstract}
Main conclusion

The introgression of the Aft allele into domesticated tomato induced a shift from flavonol to anthocyanin production in response to UV-B radiation, while the $h p-1$ allele negatively influenced the response of flavonoid biosynthesis to UV-B.
\end{abstract}

Introgression of the dominant allele Anthocyanin fruit (Aft) from Solanum chilense induces anthocyanin accumulation in the peel of tomato (Solanum lycopersicum L.) fruit. UV-B radiation can influence plant secondary metabolism regulating the expression of several genes, among which those involved in flavonoid biosynthesis.

Here, we investigated whether post-harvest UV-B treatment could up-regulate flavonoid production in tomato fruits and whether the Aft allele could affect flavonoid biosynthesis under UV-B radiation.

Mature green fruits of an anthocyanin-rich tomato mutant line (SA206) and of its wild type reference, cv. Roma, were daily subjected to post-harvest UV-B treatment until full ripening.

Up-regulation of $C H S$ and $C H I$ transcription by UV-B treatment induced flavonoid accumulation in the peel of cv. Roma. Conversely, UV-B decreased the total flavonoid content and $C H S$ transcript levels in the SA206 peel. Being SA206 a double mutant containing also $h p-1$ allele, we investigated also the behaviour of $h p-1$ fruit. The decreased peel flavonoid accumulation and gene transcription in response to UV-B suggest that $h p-1$ allele is involved in the marked down-regulation of the flavonoid biosynthesis observed in SA206 fruit. Interestingly, in SA206, UV-B radiation promoted the synthesis of delphinidin, petunidin, and malvidin by increasing $F 3^{\prime} 5^{\prime} H$ and $D F R$ transcription, but it decreased rutin production, suggesting a switch from flavonols to anthocyanins. Finally, although UV-B radiation does not reach the inner fruit tissues, it down-regulated flavonoid biosynthesis in the flesh of both genotypes. 
This study provides, for the first time, evidence that the presence of the functional Aft allele, under

UV-B radiation, redirects flavonoid synthesis towards anthocyanin production and suggests that the $h p-1$ allele negatively influences the response of flavonoid biosynthesis to UV-B.

\section{Keywords}

Anthocyanins, Flavonols, Secondary metabolism, Solanum lycopersicum L., UV-B radiation

$\begin{array}{ll}\text { Abbreviations } & \\ \text { Aft } & \text { Anthocyanin fruit } \\ \text { ANS } & \text { anthocyanidin synthase } \\ \text { CHI } & \text { chalcone isomerase } \\ \text { CHS } & \text { chalcone synthase } \\ \text { COP1 } & \text { CONSTITUTIVE PHOTOMORPHOGENIC 1 } \\ \text { DFR } & \text { dihydroflavonol 4-reductase } \\ \text { F3H } & \text { flavanone 3-hydroxylase } \\ \text { F3'H } & \text { flavonoid 3'-hydroxylase } \\ \text { F3'5'H } & \text { flavonoid 3'5'-hydroxylase } \\ \text { hp-1 } & \text { high pigment-1 } \\ \text { UVR8 } & \text { UV RESISTANCE LOCUS8 }\end{array}$




\section{Introduction}

Anthocyanins, a class of flavonoids, are water-soluble pigments responsible for the color of flowers and fruits (Grotewold 2006; Petroni and Tonelli 2011). Pollinators attraction (Shang et al. 2011), defense against UV-B solar radiation damage (Guo et al. 2008) and oxidative stress (Gould 2004) have been proposed as important functions of anthocyanins in plants. Many studies underline that anthocyanins may exert a positive effect on human health (Pojer et al. 2013). In epidemiological and preclinical studies, anthocyanins were shown to have a relevant preventing effect against cancer (Butelli et al. 2008; Wang and Stoner 2008), cardiovascular diseases (Toufektsian et al. 2008; Wallace 2011), obesity (Titta et al. 2010), diabetes (Liu et al. 2014) and degenerative pathologies, such as Alzheimer (Gutierres et al. 2014). Hidalgo et al. (2012) reported a stimulating effect of anthocyanins on the growth of Bifidobacterium spp. and Lactobacillus-Enterococcus spp., suggesting that anthocyanins and their metabolites may positively modulate the human gut microbiome.

For these reasons, foods rich in anthocyanins and other antioxidant compounds (vitamins, polyphenols, minerals) are considered "functional foods", i.e. foods that may provide a health benefit in addition to their nutrients supply (Ross 2000). Tomato (Solanum lycopersicum L.) fruits contain different antioxidant compounds (mainly lycopene), minerals, vitamins and flavonoids, but not anthocyanins (Torres et al. 2005). In tomato, anthocyanins (mainly delphinidin, malvidin and petunidin) have been found only in vegetative tissues (Bovy et al. 2002; Mes et al. 2008). However, anthocyanin synthesis can be induced in tomato fruit by using different approaches. Butelli et al. (2008) overexpressed in tomato two transcription factors (Delila, Roseal) from the "snapdragon" flower Antirrhinum majus L. These transcription factors up-regulated biosynthetic genes as phenylalanine ammonia lyase (PAL), chalcone isomerase (CHI) and flavonoid 3'5'-hydroxylase $\left(F 3^{\prime} 5^{\prime} H\right)$, this latter redirecting the biosynthetic pathway towards anthocyanin production. Traditional breeding between tomato and related wild species rich of anthocyanins, such as $S$. chilense, allowed the transfer of the dominant allele Anthocyanin fruit (Aft) (Mes et al. 2008; Jones 
et al. 2003), responsible for fruit anthocyanin pigmentation. Similarly, the Aubergine allele (Abg) from S. lycopersicoides Dunal was observed to induce pigmentation in tomato peel (Mes et al. 2008). These two genetic variants, which may be allelic according to their map position, upregulated the biosynthetic pathway of anthocyanins, including the expression of the anthocyanin synthase (ans) gene (Boches and Myers 2007).

UV-B radiation represents the highest-energy portion of the solar spectrum $(280-315 \mathrm{~nm})$ that reaches the Earth's surface. Some years have passed since a UV-B-induced pathway, which leads to the activation of several UV-B protection and repair systems, was revealed. Kliebenstein et al. (2002) discovered an Arabidopsis thaliana mutant of UV RESISTANCE LOCUS8 (UVR8) particularly sensitive to UV-B radiation, and only a few years later it was observed that UVR8 acts as UV-B photoreceptor (Rizzini et al. 2011). Different studies showed that UVR8, which is constitutively expressed as a dimer within the cells (Kaiserli and Jenkins 2007), can monomerize following UV-B exposure and move into the nucleus (Jenkins 2014). Once there, UVR8 monomer associates with CONSTITUTIVE PHOTOMORPHOGENIC 1 (COP1), and the UVR8-COP1 complex regulates the expression of several genes and transcription factors associated to UV-B acclimatization and UV-B tolerance, such as genes involved in the phenylpropanoid pathway.

Different post-harvest treatments were applied to assess their effectiveness in improving the nutraceutical value of foods and, among these, UV-B irradiation was shown to have a strong and positive effect in stimulating plant secondary metabolism (Schreiner et al. 2012). Liu et al. (2011) demonstrated that UV-B treatment can affect sensorial quality and antioxidant capacity of tomato fruit when applied at a moderate dose (20-40 $\left.\mathrm{kJ} \mathrm{m}^{-2}\right)$. Similarly, it was observed that a daily low dose $\left(6.08 \mathrm{~kJ} \mathrm{~m}^{-2} \mathrm{~d}^{-1}\right)$ of UV-B radiation influences secondary metabolism of tomato (Castagna et al. 2013, 2014) and peach (Scattino et al. 2014).

Genetic manipulation or traditional breeding are useful approaches to induce anthocyanin production in tomato fruit, which could be further stimulated by choosing the most adequate light environment. Synthesis of anthocyanins, as well as of other flavonoids, is in fact strictly controlled 
by light intensity and quality, in particular by UV-B radiation. However, at the best of our knowledge, no information is available on the UV-B influence on anthocyanin synthesis in tomato fruit. To unravel whether the effect of UV-B radiation on flavonoid biosynthesis was influenced by the presence of the dominant allele $A f t$, fruits of the anthocyanin-rich tomato mutant $S A 206$ and its wild type reference, cv. Roma, harvested at mature green stage, were daily subjected to post-harvest UV-B treatment until full ripening. Since SA206 also contains the high-pigment-1 $(h p-1)$ allele, fruits of the photomorphogenic mutant $h p-1$ were also tested.

Flavonoid quantification and expression analysis of the main flavonoid and anthocyanin biosynthetic genes were carried out in peel and flesh separately to detect possible tissue-specific effects of the UV-B radiation.

\section{Materials and methods}

\section{Chemicals}

All reagents were of analytical or HPLC grade. Organic solvents were purchased from Mallinckrodt Baker (Milan, Italy), anthocyanidin standards from Extrasynthese (Lyon, France) and all other reagents from Sigma Aldrich SRL (Milan, Italy). Water used as HPLC mobile phase was Milli-Q (Millipore, Bedford, MA, USA) purified water.

\section{Plant material and post-harvest UV-B treatment of tomato fruits}

Seeds of a tomato line homozygous for the Aft allele (referred to as $A f t$ ) were obtained from the C.M. Rick Tomato Genetics Resource Center (TGRC, http://tgrc.ucdavis.edu, accession LA1996). Seeds of the line homozygous for high-pigment-1 (referred to as $h p-1$ ) were from the collection held by the authors at the University of Tuscia. A breeding scheme to combine Aft with $h p-1$ in a processing tomato genetic background was set up with a three-way cross involving the two mutants and cv Roma. A fixed line combining Aft, $h p-1$ and the main traits typical for processing tomato 
varieties was finally selected (referred to as SA206). Due to the ideotype followed in this breeding scheme, cv Roma was chosen as the WT reference genotype for comparison with SA206.

Seeds were germinated inside Petri dishes between two wet paper sheets. After germination, the plants were transplanted in $12 \mathrm{~cm}$ diameter pots filled with a peat/pumice/commercial soil mixture (1:1:1), fertilized with $2 \mathrm{~g} / \mathrm{L}$ of $28 \mathrm{~N}-8 \mathrm{P}-16 \mathrm{~K}$ controlled release fertilizer. Subsequently, the plants were transplanted in the field under a UV-B transparent tunnel (Supplemental Fig. S1a, b). Ten plants per genotype were placed randomly inside the tunnel and sufficiently distant to ensure the most homogeneous light conditions. Tunnel (20 m long, $5 \mathrm{~m}$ wide and $2.5 \mathrm{~m}$ high) was located at

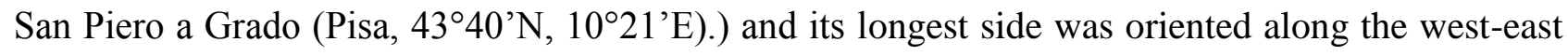
direction to allow for uniform exposure of plants to sunlight. The tunnel was covered with a plastic film, produced by Agriplast S.r.l. (Vittoria, Ragusa, Italy), whose irradiance spectrum is shown in Supplemental Fig. S1c. Healthy and sun-exposed fruits were harvested from second-third branches of different plants at the mature green stage (MG, 35-40 days post anthesis, DPA) and treated with UV-B radiation as described (Castagna et al. 2013). Briefly, fruits were randomly placed inside two different climatic chambers $\left(0.48 \mathrm{~m}^{3}\right.$, temperature $\left.20 \pm 1^{\circ} \mathrm{C}, \mathrm{RH} 80 \%\right)$, equipped with three UV-B lamp tubes (Philips Ultraviolet B, TL 20W-12RS, Koninklijke Philips Electronics, Eindhoven, The Netherlands) providing $1.69 \mathrm{~W} / \mathrm{m}^{2}$ at an approximate distance of $45 \mathrm{~cm}$ under the lamps. Irradiation was carried out daily $\left(1 \mathrm{~h}, 6.08 \mathrm{~kJ} \mathrm{~m}^{-2} \mathrm{~d}^{-1}\right)$ as long as the fruits reached the red ripe (RR) stage. Control fruits received the same treatment, but UV-B radiation was screened with a benzophenonetreated polyethylene film. Fruits were carefully peeled using a scalpel and seeds were removed from the flesh samples. For each genotype and treatment, 18 fruits (average size 40-50 g per fruit) were divided into three replicates of six fruits each and used to prepare a representative pool of peel and flesh samples. Samples were frozen in liquid nitrogen, freeze-dried (model 1700, Edwards Alto Vuoto, Milano, Italy) and stored at $-80^{\circ} \mathrm{C}$ until further analyses.

\section{Extraction and quantification of total phenolics and flavonoids}


Total phenolics were extracted in triplicate according to the method of Becatti et al. (2010), with a few modifications. Flesh $(0.5 \mathrm{~g})$ and peel $(0.1 \mathrm{~g})$ samples were finely ground with liquid $\mathrm{N}_{2}$ and extracted twice with $80 \%$ methanol aqueous solution. The liquid extract was separated through centrifugation $\left(10000 \mathrm{~g}, 15 \mathrm{~min}, 4^{\circ} \mathrm{C}\right)$, and the final volume was reduced to $5 \mathrm{ml}$ with a Rotavapor. Total phenolics were quantified with the Folin-Ciocalteau colorimetric method (Alonso Borbalán et al. 2003), based on phenol oxidation by two strong inorganic oxidants (phosphotungstic and phosphomolibdic acids) in alkaline medium Total phenolic content was expressed as mg of gallic acid/100 g FW.

Flavonoid concentration was determined according to Kim et al. (2003), and expressed as mg of catechin/100 $\mathrm{g}$ FW. The method is based on the metal-chelating property of flavonoids. The complex formation is carried out in the presence of $\mathrm{NaNO}_{2}$ and relies on the nitration of any aromatic ring with hydroxyl groups at three or four positions unsubstituted or not sterically blocked. Addition of $\mathrm{AlCl}_{3}$ determines the formation of a (yellow) complex which immediately after $\mathrm{NaOH}$ addition becomes red. Briefly, $60 \mu \mathrm{L}$ of $5 \% \mathrm{NaNO}_{2}, 40 \mu \mathrm{L}$ of $10 \% \mathrm{AlCl}_{3}, 400 \mu \mathrm{L}$ of $1 \mathrm{M} \mathrm{NaOH}, 200$ $\mu \mathrm{L}$ of distilled water and $100 \mu \mathrm{L}$ of extract were mixed and the absorbance was recorded at $510 \mathrm{~nm}$.

\section{Identification and quantification of flavonoids by HPLC-DAD}

Extracts were filtered with $0.45 \mu \mathrm{m}$ Minisart filters (Sartorius Stedim Biotech, Goettingen, Germany) and analysed by a Spectra System P4000 HPLC equipped with a UV 6000 LP photodiode array detector (Thermo Fisher Scientific, Waltham, MA, USA) using a Phenomenex Prodigy LC-18 RP column (5 $\mu$ m particle size, 250 x 4.6 mm, Phenomenex Italia, Castel Maggiore,

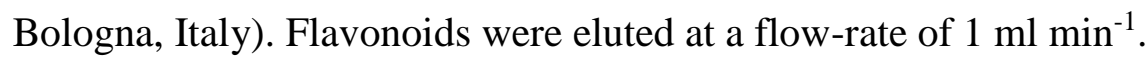

Water acidified to $\mathrm{pH} 2.7$ with formic acid served as solvent A and $100 \%$ methanol as solvent B, according to the following gradient: solvent B: $10 \%$ (0-5 min), 10-30\% (5-20 min), 30-90\% (20$28 \mathrm{~min}), 90-10 \%(28-35 \mathrm{~min}), 10 \%(35-40 \mathrm{~min})$, followed by $5 \mathrm{~min}$ re-equilibration in the initial condition before the next injection. Commercial standards of quercetin, rutin, naringenin, 
delphinidin chloride, cyanidin chloride and pethunidin chloride were used for external calibration curves. Rutin and quercetin were detected at $350 \mathrm{~nm}$, naringenin at $280 \mathrm{~nm}$ and the three anthocyanidins at $520 \mathrm{~nm}$.

\section{RNA isolation and real time RT-PCR analyses}

RNA was isolated from samples of $3 \mathrm{~g}$ of peel and flesh from wild-type cv Roma and SA206 mutant fruits, as previously described (Calvenzani et al, 2010). First strand cDNA synthesis was obtained from about $5 \mu \mathrm{g}$ of total RNA using the RT Superscript ${ }^{\mathrm{TM}}$ II (Invitrogen, Carlsbad, CA, USA) and an oligo dT, as previously described (Procissi et al. 1997).

To verify whether flavonoid biosynthetic genes from Roma and SA206 were different from the Money-Maker reference genome, partial cDNA sequences of $C H S, C H I, F 3 H, F 3$ ' $H, F 3$ '5 ' $H, D F R$, ANS biosynthetic genes and EF1 reference gene were isolated from peel of SA206 mutant using Phusion High Fidelity DNA polymerase (New England Biolabs, Ipswich, MA, USA) and oligonucleotides designed on cv Money-Maker indicated in Table 1. After purification, PCR products were cloned in PCR4 Blunt TOPO vector (Invitrogen) and sequenced. Primers used for real time RT-PCR analysis were designed on sequences obtained and are indicated in Table 2. Sequences from SA206 were identical to those of cv Roma.

Quantitative real time RT-PCR analysis was performed with the Cfx $96^{\mathrm{TM}} \mathrm{BioRad}$ Real Time system in a final volume of $20 \mu \mathrm{L}$ containing $5 \mu \mathrm{L}$ of 50 -fold diluted cDNA, $0.2-0.4 \mu \mathrm{M}$ of each primer, and $10 \mu \mathrm{L}$ of $2 \mathrm{X}$ iQ SYBR Green Supermix (BioRad Laboratories, Hercules, CA, USA). As a reference for normalization, we used the LeEF1 gene, encoding the tomato ELONGATION FACTOR 1- $\alpha$, because of its high and stable expression in mature tomato fruit (Bartley and Ishida 2003) by using primers LeEF1-F4 and LeEF1-R3 (Table 2). Relative quantification was analysed using Cfx Manager Software version 1.6 (BioRad Laboratories).

The protocol used was as follows: $95^{\circ} \mathrm{C}$ for $2 \mathrm{~min}, 55$ cycles of $95^{\circ} \mathrm{C}$ for $15 \mathrm{~s}$, and $60{ }^{\circ} \mathrm{C}$ for $30 \mathrm{~s}$. A melt curve analysis was performed following every run to ensure a single amplified product for 
each reaction. Relative quantification of the target RNA expression level was performed using the comparative Ct method (UserBulletin 2, ABI PRISM7700 Sequence Detection System, Dec 1997; Perkin- Elmer Applied Biosystems) in which the differences in the Ct (threshold cycle) for the target RNA and endogenous control RNA, called $\Delta \mathrm{Ct}$, were calculated to normalize for the differences in the total amount of cDNA present in each reaction and the efficiency of the reverse transcription. Finally, the target RNA expression level was obtained from the equation $2^{-\Delta \Delta \mathrm{Ct}}$ and expressed relative to a calibrator. Standard errors of $\mathrm{Ct}$ values were obtained from measurements performed in triplicate.

\section{Statistical analysis}

Statistical analysis was carried out with the NCSS 2000 (NCSS Statistical Software, Kaysville, Utah, USA) statistical software. Data were analysed by one-way ANOVA followed by TukeyKramer post hoc test at the significance level $P \leq 0.05$, to evaluate the effect of UV-B irradiation on each genotype and tissue separately. Data reported in the figures represent the mean of three biological replications $\pm \mathrm{SE}$.

\section{Results}

UV-B radiation induces an opposite effect on phenolic and flavonoid accumulation in peel and flesh of cv Roma and negatively affects their content in both tissues of the SA206 mutant Differences between the two genotypes in the constitutive levels of phenolics and flavonoids were evident. SA206 peel was richer than Roma in phenolics $(+164 \%)$ and flavonoids $(+247 \%)$, while the opposite trend was evident in the flesh $(-21 \%$ and $-38 \%$, phenolics and flavonoids, respectively; Fig 1). In both genotypes, phenolics and flavonoids were more concentrated in the peel. Differences were particularly evident in SA206 fruit, which showed about 16-fold and 38-fold higher levels of phenolics and flavonoids in the peel. In cv Roma peel, phenolics and flavonoids were about 4-fold and 6-fold more concentrated than in the flesh, respectively. Even if differences between peel and 
flesh are reduced by expressing data on a dry weight basis (data not shown), they are not

suppressed. Flesh is composed by multiple tissues (pericarp, columella, placenta, locular and vascular tissues), characterized by different flavonoid and phenolic content and composition. This could result in a dilution effect by poorly concentrated tissues.

UV-B post-harvest treatment induced an increased accumulation of phenolics (47\%) and flavonoids (67\%) in the peel of cv Roma (Fig. 1a, e). The positive effect played by UV-B radiation was evident starting from the early stages of the biosynthetic pathway, leading to a marked accumulation of naringenin, whose concentration was more than 4.5-fold higher than in control (Fig. 2a). Similarly, quercetin and rutin were more abundant in the peel of UV-B-treated fruit (about $210 \%$ and $140 \%$, respectively; Fig. 2e, i).

Differently from what occurred in the peel, UV-B radiation led to a slight, though significant, reduction in phenolic and flavonoid concentration in the flesh (-18\% and $-24 \%$, respectively, Fig. 1 b, f). Naringenin was unaffected by the UV-B treatment, while quercetin and rutin levels were considerably lower (-70\% and $-78 \%$, respectively, Fig. 2b, f, j).

Following post-harvest UV-B irradiation, SA206 fruits showed a lower concentration of total phenolics and flavonoids compared to the control, both in peel (-37\% and $-38 \%$, respectively, Fig. 1c, g) and flesh (-30\% and $-24 \%$, respectively, Fig. 1d, h).

Among flavonoids, rutin was negatively affected by UV-B irradiation in the peel (-28\%, Fig. 2k), while naringenin and quercetin concentration did not vary significantly (Fig. 2 c, g). Similarly to what observed in the peel, no UV-B-induced difference was observed in naringenin concentration also in SA206 flesh, while quercetin and rutin levels significantly decreased following UV-B treatment (-82\%, and $-73 \%$, respectively; Fig. $2 \mathrm{~d}, \mathrm{~h}, 1)$.

Expression of flavonoid biosynthetic genes was differently influenced by UV-B radiation in peel and flesh of cv Roma and negatively affected by UV-B treatment in the SA206 mutant 
In accordance with the positive effect of UV-B radiation on flavonoid accumulation, $\mathrm{CHS}$ and $\mathrm{CHI}$ were significantly more expressed in the peel of UV-B irradiated fruit of cv Roma (30\% and about 19-fold, respectively; Fig. 3a, e). However, in this tissue, $F 3 H$ and $F 3$ ' $H$ were unaffected by the treatment (Fig. 3i, m).

Differently to what observed in the peel, UV-B radiation determined a lower transcript level of $C H S$ and $\mathrm{CHI}$ in the flesh of cv Roma fruit (-78\% and $-52 \%$, respectively, Fig. 3b, f), in agreement with the reduction of total flavonoid concentration. UV-B radiation exerted a positive effect on $F 3 H$ and F3'H, whose transcript levels were about 5.7- and 8.4-fold higher than in control flesh (Fig. 3j, n). In SA206 fruit, UV-B treatment reduced transcript level of flavonoid biosynthetic genes similarly in both tissues, in agreement with the reduced content of flavonoids. More in details, in the peel, all genes investigated were down-regulated by UV-B radiation (Fig. 3c, g, k, o), with the decrease in the transcript levels ranging from $-35 \%(C H I)$ up to $-99 \%(F 3 H)$. Similarly, in the flesh, UV-B radiation induced a significant decrease in the expression of flavonoid biosynthetic genes. The lowest transcript level was observed for $C H S$ and $C H I$ (-94\% and $-90 \%$, respectively, Fig. 3d, h), followed by $F 3$ ' $H(-57 \%)$ and $F 3 H(-56 \%$, Fig. 31, p).

\section{UV-B radiation increases anthocyanin accumulation in the peel of the $S A 206$ mutant}

The mutant fruit is able to synthesise anthocyanins, which accumulate in the peel as purple spots (Fig. 4b). HPLC analysis revealed the presence of delphinidin, petunidin and malvidin glycosides, which were quantified as anthocyanidin after acidic hydrolysis. Malvidin and delphinidin were the main anthocyanidins in the control peel (41\% and 37\%, respectively). No anthocyanins were detected in the flesh of SA206 mutant, as well as in both tissues of cv Roma (not shown).

UV-B treatment induced a significant increase in the accumulation of all the anthocyanidins detected. Petunidin showed the highest increase (about 3.4-fold), followed by malvidin (2.3-fold) and delphinidin (1.4-fold; Fig. 5a-c). A parallel increase in the transcript levels of $F 3^{\prime} 5^{\prime} H$ and $D F R$ 
genes was observed in UV-B-treaded samples (about 12- and 3.4-fold, respectively; Fig. 5d, e), while ANS expression level was unaffected (Fig. 5f).

\section{UV-B radiation down-regulates flavonoid biosynthesis in $h p-1$ peel}

Marked differences were observed between the two tissues, phenolics and flavonoids being respectively 7 -fold and 37-fold more concentrated in the peel than in the flesh (Fig. 6a-d).

Phenolic and flavonoid concentration was unaffected by UV-B treatment in $h p-1$ flesh (Fig. 7b, d), while it underwent a significant decrease in the peel $(-28 \%$ and $-41 \%$, for phenolics and flavonoids, respectively; Fig. 6a, c). A marked decrease in all flavonoids investigated was detected in $h p-1$ peel following UV-B treatment (Fig. 6e, g, k), ranging from $-33 \%$ (quercetin) to $-49 \%$ (naringenin). Conversely, UV-B irradiation induced naringenin $(+90 \%)$ and quercetin $(+56 \%)$ accumulation in the flesh (Fig. 6f, h).

A marked reduction in the transcript levels of all genes tested was observed in $h p-1$ peel following UV-B treatment, ranging from $-29 \%\left(F 3^{\prime} H\right)$ to $-69 \%(C H S)$ (Fig. 6m, o, q, s), in accordance with the lower flavonoid concentration detected in this genotype. Gene transcription in the flesh was extremely low and differentially influenced by UV-B radiation (Fig. 6n, p, r, t), since $C H S$ and $F 3$ ' $H$ were more transcribed in control fruit while $C H I$ transcription was enhanced in UV-B-treated sample.

\section{Discussion}

The present work aimed to investigate the effect of post-harvest UV-B radiation on flavonoid biosynthesis in tomato fruit and to understand whether and how this response was influenced by the presence of the dominant allele $A f t$, responsible for anthocyanin production in fruit.

Gene expression analysis revealed that the UV-B-induced accumulation of flavonoids in the peel of cv Roma tomatoes resulted from an increased transcription of the genes involved in the early stages 
of the flavonoid biosynthetic pathway, namely $C H S$ and, even more, $C H I$. The positive effect of UV-B radiation on the flavonoid level has been previously reported in different fruits. Hagen et al. (2007) found that the supplementation of UV-B radiation determined an accumulation of total flavonoids, in particular of quercetin glycosides and anthocyanins in apple fruit. Post-harvest UV-B irradiation was effective also on European pear fruits (P. communis, Qian et al. 2013) and Chinese sand pear fruits (P. pyrifolia, Sun et al. 2014).

In Arabidopsis, the flavonoid pathway is activated by two different sets of transcription factors, controlling the early (i.e. AtMYB11/12/111) or the late (i.e. the MYB-bHLH-WD40 complex) biosynthetic genes (Stracke et al. 2010; Petroni and Tonelli 2011). The major effector of UVR8mediated gene expression is the ELONGATED HYPOCOTYL 5 (HY5) transcription factor, that controls many of the downstream target genes, among which MYB12 (Stracke et al. 2010), the negative regulator of phenylpropanoids MYB4 (Hemm et al. 2001), and PAP1, one of four R2R3 MYB activators involved in anthocyanin biosynthesis (Shin et al. 2013).

According to Ravaglia et al. (2013), transcription of PpFLS1 increased in nectarines (cv. Stark Red Gold), suggesting an accumulation of flavonols after $72 \mathrm{~h}$ of UV-B treatment, possibly due to the involvement of the transcription factor PpMYB10, particularly sensitive to UV-B. It is possible that, also in tomato, transcription factors belonging to the MYB family, as SIMYB12, that controls the flavonol synthesis by predominantly activating the early biosynthetic genes (Adato et al. 2009; Ballester et al. 2010), are strongly responsive to UV-B radiation, causing an overall up-regulation of the flavonoid biosynthetic pathway and, in turn, flavonoid accumulation.

Whereas the UV-B treatment increased the flavonoid level in the peel of the cv Roma, it decreased it in SA206 mutant. A genotype-dependent effect of UV-B radiation on flavonoid accumulation and expression of related genes was previously observed in tomato fruits of commercial cultivars (Giuntini et al. 2008). Similarly, the photoresponsive tomato mutant ( $h p-1)$ and its wild type, ripened in planta under photoselective films, exhibited an opposite response in UV-B-depleted conditions (Calvenzani et al. 2010). In particular, while flavonoids were severely affected in UV-B- 
depleted peel of wild type fruit, in the $h p-1$ mutant UV-B depletion did not greatly alter flavonoid concentration in the peel but significantly increased it in the flesh. Marked genotype-related differences were described also by Scattino et al. (2014), who treated peaches (cv. Suncrest and cv. Babygold 7) and nectarines (cv. Big Top) with up to $36 \mathrm{~h}$ of UV-B radiation. A higher accumulation of flavonol-glycosydes and anthocyanins was observed in treated fruits of cv. Big Top and cv. Suncrest, while the fruits of cv. Babygold responded to the UV-B irradiation by decreasing the levels of anthocyanins and flavonols.

Downstream from naringenin, the flavonoid biosynthetic pathway diverges into several branches. $\mathrm{F} 3 \mathrm{H}$ drives the production of dihydroflavonols, catalyzing the stereospecific $3 \beta$-hydroxylation of (2S)-flavanone. The hydroxylation pattern is a major determinant of the anthocyanin color. Hydroxylation of the $\mathrm{B}$ ring by $\mathrm{F}^{\prime} \mathrm{H}^{\mathrm{H}}$ and $\mathrm{F}^{\prime}{ }^{\prime}$ ' $^{\prime} \mathrm{H}$ leads to production of red di-hydroxylated and blue tri-hydroxylated anthocyanins, respectively. Transcription of $F 3^{\prime} 5^{\prime} H$ gene seems to be necessary to activate anthocyanin production in tomato (Bovy et al. 2002), as indicated by the presence of only delphinidin-derived anthocyanins. In accordance with this report, in the peel of the SA206 mutant only delphinidin, malvidin and petunidin glycosides were detected.

The lower transcription of $F 3 H$ and $F 3^{\prime} H$ in $S A 206$ peel after irradiation with UV-B suggests that levels of dihydroflavonols would be lower as well and a minor concentration of anthocyanins would be expected. Interestingly, UV-B radiation instead led to increased anthocyanin synthesis, while decreasing flavonol production, suggesting that UV-B radiation by enhancing $F 3^{\prime} 5^{\prime} H$ could promote the conversion of dihydrokaempferol to dihydromyricetin, which is then used by the tomato DFR enzyme to drive the synthesis of anthocyanins. In Solanaceous species, the DFR enzyme is in fact specific for dihydromyricetin and does not accept dihydrokaempferol as a substrate (Bovy et al. 2002).

Despite the ANS gene was unaffected by the UV-B treatment, a higher $F 3$ ' 5 ' $H$ and $D F R$ expression was indeed observed in SA206 UV-B-treated samples, that may explain the increased production of anthocyanins in the UV-B treated fruit. It therefore seems that, compared with cv Roma, in the 
anthocyanin-rich mutant post-harvest UV-B irradiation plays an opposite role on anthocyanin and

flavonol accumulation, probably acting on different sets of regulatory factors. Recently, Kiferle et al. (2015) carried out a molecular and functional characterization of two genes encoding tomato transcription factors belonging to the R2R3-MYB family, Anthocyanin1 (SlANT1) and Anthocyanin2 (SlAN2), both involved in activation of anthocyanin synthesis (Mathews et al. 2003; Schreiber et al. 2012; Meng et al. 2015). However, only SIAN2 was found to positively regulate anthocyanin synthesis in response to high light in vegetative tissues (Kiferle et al. 2015). Interestingly, the Aft gene probably encodes Anthocyanin1 (SlANT1; Schreiber et al. 2012) or SlAN2 (Boches and Myers 2007).

Although the absolute levels of anthocyanidins of SA2016 tomato peel are very low as compared to other purple fruits, such as black grape or blueberry, UV-B treatment increased by 2.4 -fold their content. This increases the nutraceutical value of Aft $h p-1$ tomatoes compared to commercial varieties, also considering that tomato is largely consumed in the Mediterranean region. Because the content of anthocyanins in the fruit peel is in turn increased in genotypes combining Aft with the recessive variant atroviolaceum (atv) (Mazzucato et al. 2013), it will be of great interest to evaluate the effect of UV-B irradiation on fruits from purple tomato lines.

In accordance with our data, Ravaglia et al. (2013) and Scattino et al. (2014) found an up-regulation of the anthocyanin metabolism after post-harvest UV-B exposure in the skin of peach and nectarines. Similarly, UV-B radiation was able to increase the content of anthocyanins in apple fruit (Hagen et al. 2007). Recent studies confirmed the positive effect of UV-B exposure on the anthocyanin levels in apple skin, probably due to a higher expression of MdMYBA (Ban et al. 2007; Peng et al. 2013).

In the light of the possible role of the Aft gene product as a transcription factors belonging to the R2R3-MYB family (Boches and Myers 2007; Schreiber et al. 2012), an involvement of Aft in the mechanism of UV-B control of flavonoid synthesis cannot be excluded. MYB12, a member of the 
R2R3-MYB family, is in fact known to be transcribed under the control of the UVR8-mediated HY5 transcription factor (Stracke et al. 2010). The increased anthocyanin synthesis accompanied by a decreased flavonoid accumulation suggests that the presence of Aft negatively influences the response of the flavonoid biosynthetic pathway to UV-B radiation. However, since SA206 is a double mutant containing both the Aft and the $h p-1$ alleles, we tested the hypothesis that the negative effect on flavonoid pathway could be imposed by $h p-1$ rather than by Aft, by studying the response to UV-B of the tomato mutant $h p-1$. Indeed, lower transcript levels of the assayed flavonoid biosynthetic genes were detected in the peel of $h p-l$ UV-B treated fruit, accompanied by a significant decrease in the content of individual and total flavonoids. Such a negative response to UV-B radiation suggests that $h p-1$ is involved in the marked down-regulation of the flavonoid biosynthesis in SA206 peel. Tomato plants carrying $h p l$ mutation are characterized by exaggerated light responsiveness and photomorphogenic response. $H P 1$ gene encodes the tomato homologue of DDB1, a light signal transduction proteins that in Arabidopsis participates to the formation of the complex CUL4-DDB1-COP1-SPA, a CUL4-DDB1-based E3 ubiquitin ligase that suppresses the photomorphogenic program by targeting the transcription factor HY5 for degradation (Huang et al. 2013). In tomato, HP1/SIDDB1 is an essential component of CUL4-based E3 ligase complex (Wang et al. 2008). Since under UV-B radiation, UVR8 monomer sequesters COP1 from DDB1, causing physical dissociation and consequent loss of function of the complex, a role for HP1/SIDDB1 in the response to UV-B radiation cannot be excluded.

In our study, UV-B effects were not only genotype-dependent, but also tissue-dependent. In cV. Roma, UV-B irradiation positively stimulated the whole flavonoid pathway in the peel, while decreasing total flavonoids as well as the $C H S$ and the $C H I$ transcript levels in the flesh. Similarly, a lower flavonoid accumulation and related gene transcription occurred also in the flesh of the SA206 mutant. A similar finding has been already observed in the flesh of tomato fruits ripened under UVB-depleted conditions that generally showed a flavonoid concentration and gene expression level higher than controls (Calvenzani et al. 2010), indicating a negative influence played by UV-B 
radiation in this tissue. Differences between peel and flesh were also detected in $h p-1$ fruit, where

total phenolics and flavonoids were unaffected by UV-B radiation in the flesh but decreased in the peel. At gene expression level, $C H I$ behaved in the opposite way between peel and flesh, leading to decreased or increased naringenin level, respectively. Light transmittance across tomato peel is very low (below 10\%) and dramatically falls in the UV region (about 0.5\%; Åke Strid, personal communication). However, despite UV-B is unlikely to directly reach the inner fruit tissues, our results demonstrate that this radiation can affect flesh flavonoid biosynthesis probably mediated by a signal transmission pathway. Specifically targeted studies are needed to elucidate the nature of signals that mediate flavonoid synthesis in response to UV-B in the flesh.

In conclusion, it clearly emerges that UV-B radiation influences flavonoid accumulation differentially in the peel of the different genotypes tested, acting as a positive regulator of flavonoid synthesis in cv. Roma while down-regulating it in SA206 and $h p-1$ mutants. The introgression of the Aft allele into domesticated tomato, and the consequent ability to produce anthocyanins in the fruit, apparently negatively influences the capacity to react to UV-B radiation by the flavonoid biosynthetic pathway. However, this behavior is likely due to the $h p-1$ allele, being SA206 a double mutant containing both $h p-1$ and the Aft alleles.

On the other hand, UV-B treatment exerted a significant positive effect on the anthocyanins synthesis in the peel of the SA206 mutant, leading to a more than double increase in malvidin, delphinidin and petunidin concentration. Although ANS did not show any change in the expression fold, $F 3^{\prime} 5^{\prime} H$ and $D F R$ were considerably up-regulated by UV-B, indicating a shift from flavonol to anthocyanin production induced by the UV-B treatment. This study provides, for the first time, evidence that the $h p-1$ allele negatively affects flavonoid biosynthesis under UV-B radiation while the presence of functional A $f t$ allele redirects it towards anthocyanin production.

\section{References}

Adato A, Mandel T, Mintz-Oron S, Venger I, Levy D, Yativ M, Domínguez E, Wang Z, De Vos 
RCH, Jetter R, Schreiber L, Heredia A, Rogachev I, Aharoni A (2009) Fruit-surface flavonoid accumulation in tomato is controlled by a SLMYB12-regulated transcriptional network. PLoS Genetics 5 (12): e1000777

Alonso Borbalán ÁM, Zorro L, Guillén DA, García Barroso C (2003) Study of the polyphenol content of red and white grape varieties by liquid chromatography-mass spectrometry and its relationship to antioxidant power. J Chromat A 1012:31-38

Ballester AR, Molthoff J, de Vos R, Hekkert BTL, Orzaez D, Fernández Moreno JP, Tripodi P, Grandillo S, Martin C, Heldens J, Ykema M, Granell A, Bovy A (2010) Biochemical and molecular analysis of pink tomatoes: deregulated expression of the gene encoding transcription factor SIMYB12 leads to pink tomato fruit color. Plant Physiol 152 (1): 71-84

Ban Y, Honda C, Hatsuyama Y, Igarashi M, Bessho H, Moriguchi T (2007) Isolation and functional analysis of a MYB Transcription factor gene that is a key regulator for the development of red coloration in apple skin. Plant Cell Physiol 48 (7):958-970

Bartley GE, Ishida BK (2003) Developmental gene regulation during tomato fruit ripening and in vitro sepal morphogenesis. BMC Plant Biol 3:4

Becatti E, Chkaiban L, Tonutti P, Forcato C, Bonghi C, Ranieri A (2010) Short-term postharvest carbon dioxide treatments induce selective molecular and metabolic changes in grape berries. $\mathbf{J}$ Agr Food Chem 58 (13):8012-8020

Boches P, Myers J (2007) The anthocyanin fruit tomato gene (Aft) is associated with a DNA polymorphism in a MYB transcription factor. Hort Sci 42: 856

Bovy A, De Vos R, Kemper M, Schijlen E, Almenar Pertejo M, Muir S, Collins G, Robinson S, Verhoeyen M, Hughes S, Santos-Buelga C, van Tunen A (2002) High-flavonol tomatoes resulting from the heterologous expression of the maize transcription factor genes $L C$ and $C l$. Plant Cell 14:2509-2526

Butelli E, Titta L, Giorgio M, Mock HP, Matros A, Peterek S, Schijlen EG, Hall RD, Bovy AG, Luo J, Martin C (2008) Enrichment of tomato fruit with health-promoting anthocyanins by 
expression of select transcription factors. Nature Biotechnol 26 (11):1301-1308

Calvenzani V, Martinelli M, Lazzeri V, Giuntini D, Dall'Asta C, Galaverna G, Tonelli C, Ranieri A, Petroni K (2010) Response of wild-type and high pigment-1 tomato fruit to UV-B depletion: flavonoid profiling and gene expression. Planta 231 (3): 755-765

Castagna A, Chiavaro E, Dall'Asta C, Rinaldi M, Galaverna G, Ranieri A (2013) Effect of Postharvest UV-B irradiation on nutraceutical quality and physical properties of tomato fruits. Food Chem 137 (1-4):151-158

Castagna A, Dall'Asta C, Chiavaro E, Galaverna G, Ranieri A (2014) Effect of post-harvest UV-B irradiation on polyphenol profile and antioxidant activity in flesh and peel of tomato fruits. Food Bioproc Technol 7 (8):2241-2250

Giuntini D, Lazzeri V, Calvenzani V, Dall'Asta C, Galaverna G, Tonelli C, Petroni C, Ranieri A (2008) Flavonoid profiling and biosynthetic gene expression in flesh and peel of two tomato genotypes grown under UV-B-depleted conditions during ripening. J Agr Food Chem 56 (14):5905-5915

Gould K (2004) Nature's Swiss army knife: the diverse protective roles of anthocyanins in leaves. J Biomed Biotechnol 5 (5): 314-320

Grotewold E (2006) The genetics and biochemistry of floral pigments. Annu Rev Plant Biol $57: 761-780$

Guo J, Han W, Wang M-H (2008) Ultraviolet and environmental stresses involved in the induction and regulation of anthocyanin biosynthesis: a review. African J Biotechnol 7 (25):4966-4972 Gutierres JM, Carvalho FB, Schetinger MRC, Marisco P, Agostinho P, Rodrigues M, Rubin MA, Schmatz R, da Silva CR, Cognato GdP, Farias JG, Signor C, Morscha VM, Mazzanti CM, Bogo M, Bonan CD, Spanevello R (2014) Anthocyanins restore behavioral and biochemical changes caused by streptozotocin-induced sporadic dementia of Alzheimer's type. Life Sci 96 $(1-2): 7-17$

Hagen SF, Borge GIA, Bengtsson GB, Bilger W, Berge A, Haffner K, Solhaug KA (2007) Phenolic 
contents and other health and sensory related properties of apple fruit (Malus domestica

Borkh., cv. Aroma): effect of postharvest UV-B irradiation. Postharv Biol Technol 45 (1):1-10

Hemm MR, Herrmann KM, Chapple C (2001) AtMYB4: a transcription factor general in the battle against UV. Trends Plant Sci 6:135-136

Hidalgo M, Oruna-Concha MJ, Walton GE, Kallithraka S, Spencer JPE, Gibson GR, de PascualTeresa S (2012) Metabolism of anthocyanins by human gut micro flora and their influence on gut bacterial growth. J Agric Food Chem 60:3882-3890

Huang X, Ouyang X, Yang P, Lau OS, Chen L, Wei N, Deng XW (2013) Conversion from CUL4based COP1-SPA E3 apparatus to UVR8-COP1-SPA complexes underlies a distinct biochemical function of COP1 under UV-B. Proc Natl Acad Sci USA 110 (41): 16669-16674

Jenkins GI (2014) Structure and function of the UV-B photoreceptor UVR8. Curr Opin Struct Biol 29:52-57

Jones CM, Mes P, Myers JR (2003) Characterization and inheritance of the Anthocyanin fruit (Aft) tomato. J Hered 94 (6):449-456

Kaiserli E, Jenkins GI (2007) UV-B promotes rapid nuclear translocation of the Arabidopsis UV-B specific signaling component UVR8 and activates its function in the nucleus. Plant Cell 19 (8):2662-2673

Kiferle C, Fantini E, Bassolino L, Povero G, Spelt C, Buti S, Giuliano G, Quattrocchio F, Koes R, Perata P, Gonzali S (2015) Tomato R2R3-MYB proteins SlANT1 and SlAN2: same protein activity, different roles. PLoS ONE 10 (8):1-20

Kim DO, Chun OK, Kim YJ, Moon HY, Lee CY (2003) Quantification of polyphenolics and their antioxidant capacity in fresh plums. J Agr Food Chem 51 (22):6509-6515

Kliebenstein DJ, Lim JE, Landry LG, Last RL (2002) Arabidopsis UVR8 regulates Ultraviolet-B signal transduction and tolerance and contains sequence similarity to human regulator of chromatin condensation 1. Plant Physiol 130 (1): 234-243

Liu C, Han X, Cai L, Lu X, Ying T, Jiang Z (2011) Postharvest UV-B irradiation maintains sensory 
qualities and enhances antioxidant capacity in tomato fruit during storage. Postharvest Biol Technol 59 (3):232-237

Liu Y, Li D, Zhang Y, Sun R, Xia M (2014) Anthocyanin increases adiponectin secretion and protects against diabetes-related endothelial dysfunction. Am J Physiol Endocrinol Metab 306:E975-E988

Mathews H. Clendennen SK, Caldwell CG, Liu XL, Connors K, Matheis N, Schuster DK, Menasco DJ, Wagoner W, Lightner J, Wagner DR (2003) Activation tagging in tomato identifies a transcriptional regulator of anthocyanin biosynthesis, modification, and transport. Plant Cell 15 (8):1689-1703

Mazzucato A, Willems D, Bernini R, Picarella ME, Santangelo E, Ruiu F, Tilesi F, Soressi GP (2013) Novel phenotypes related to the breeding of purple-fruited tomatoes and effect of peel extracts on human cancer cell proliferation. Plant Physiol Biochem 72:125-133

Meng X, Yang D, Li X, Zhao S, Sui N, Meng Q (2015) Physiological changes in fruit ripening caused by overexpression of tomato SIAN2, an R2R3-MYB factor. Plant Physiol Biochem $89: 24-30$

Mes PJ, Boches P, Myers JR, Durst R (2008) Characterization of tomatoes expressing anthocyanin in the fruit. J Amer Soc Hort Sci 133 (2):262-269

Peng T, Saito T, Honda C, Ban Y, Kondo S, Liu JH, Hatsuyama Y, Moriguchi T (2013) Screening of UV-B-induced genes from apple peels by SSH: possible involvement of MdCOP1-mediated signaling cascade genes in anthocyanin accumulation. Physiol Plant 148 (3):432-444

Petroni K, Tonelli C (2011) Recent advances on the regulation of anthocyanin synthesis in reproductive organs. Plant Sci 181 (3):219-229

Pojer E, Mattivi F, Johnson D, Stockley CS (2013) The case for anthocyanin consumption to promote human health : a review. Comp Rev Food Sci Food Safety 12:483-508.

Procissi A, Dolfini S, Ronchi A, Tonelli C (1997) Light-dependent spatial and temporal expression of pigment regulatory genes in developing maize seeds. Plant Cell 9:1547-1557 
Qian M, Zhang D, Yue X, Wang S, Li X, Teng Y (2013) Analysis of different pigmentation patterns in 'Mantianhong' (Pyrus pyrifolia Nakai) and 'Cascade' (Pyrus Communis L.) under bagging treatment and postharvest UV-B/visible irradiation conditions. Sci Hort 151:75-82

Ravaglia D, Espley RV, Henry-Kirk RA, Andreotti C, Ziosi V, Hellens RP, Costa G, Allan AC (2013) Transcriptional regulation of flavonoid biosynthesis in nectarine (Prunus persica) by a set of R2R3 MYB transcription factors. BMC Plant Biol 13:68

Rizzini L, Favory JJ, Cloix C, Faggionato D, O’Hara A, Kaiserli E, Baumeister R, Schäfer E, Nagy F, Jenkins GI, Ulm R (2011) Perception of UV-B by the Arabidopsis UVR8 protein. Science 332:103-106

Ross S (2000) Functional foods: the food and drug administration perspective. Am J Clin Nutr 71(6):1735S-1738S

Scattino C, Castagna A, Neugart S, Chan HM, Schreiner M, Crisosto CH, Tonutti P, Ranieri A (2014) Post-harvest UV-B irradiation induces changes of phenol contents and corresponding biosynthetic gene expression in peaches and nectarines. Food Chem 163:51-60

Schreiber G, Reuveni M, Evenor D, Oren-Shamir M, Ovadia R, Sapir-Mir M, Bootbool-Man A, Nahon S, Shlomo H, Chen L, Levin I (2012) ANTHOCYANIN1 from Solanum chilense is more efficient in accumulating anthocyanin metabolites than its Solanum lycopersicum counterpart in association with the ANTHOCYANIN FRUIT phenotype of tomato. Theor Appl Genet 124 (2):295-307

Schreiner M, Mewis I, Huyskens-Keil S, Jansen MAK, Zrenner R, Winkler JB, O’Brien N, Krumbein A (2012) UV-B-induced secondary plant metabolites - potential benefits for plant and human health. Crit Rev Plant Sci 31:229-240

Shang Y, Venail J, Mackay S, Bailey PC, Schwinn KE, Jameson PE, Martin CR, Davies KM (2011) The molecular basis for venation patterning of pigmentation and its effect on pollinator attraction in flowers of Antirrhinum. New Phytol 189 (2):602-615 
Shin DH, Choi MG, Kim K, Bang G, Cho M, Choi S-B, Choi G, Park Y-II (2013) HY5 regulates anthocyanin biosynthesis by inducing the transcriptional activation of the MYB75/PAP1 transcription factor in Arabidopsis. FEBS Lett 587: 1543-1547

Stracke R, Favory J-J, Gruber H, Bartelniewoehner L, Bartels S, Binkert M, Funk M, Weisshaar B, Ulm R (2010). The Arabidopsis bZIP transcription factor HY5 regulates expression of the PFG1/MYB12 gene in response to light and ultraviolet-B radiation. Plant Cell Environ 33: 88103

Sun Y, Qian M, Wu R, Niu Q, Teng Y, Zhang D (2014) Postharvest pigmentation in red chinese sand pears (Pyrus pyrifolia Nakai) in response to optimum light and temperature. Postharvest Biol Technol 91:64-71

Titta L, Trinei M, Stendardo M, Berniakovich I, Petroni K, Tonelli C, Riso P, Porrini M, Minucci S, Pelicci PG, Rapisarda P, Reforgiato Recupero G, Giorgio M (2010) Blood orange juice inhibits fat accumulation in mice. Int J Obesity 34 (3):578-588

Torres CA, Davies NM, Yañez JA, Andrews PK (2005) Disposition of selected flavonoids in fruit tissues of various tomato (Lycopersicon esculentum Mill.) genotypes. J Agr Food Chem 53 (24):9536-9543

Toufektsian MC, de Lorgeril M, Nagy N, Salen P, Donati MB, Giordano L, Mock HP, Peterek S, Matros A, Petroni K, Pilu R, Rotilio D, Tonelli C, de Leiris J, Boucher F, Martin C (2008) Chronic dietary intake of plant-derived anthocyanins protects the rat heart against ischemiareperfusion injury. J Nutr 138 (4):747-752

Wallace TC (2011) Anthocyanins in cardiovascular disease. Adv Nutr 2 (7):1-7

Wang S, Liu J, Feng Y, Niu X, Giovannoni J, Liu Y (2008) Altered plastid levels and potential for improved fruit nutrient content by downregulation of the tomato DDB1-interacting protein CUL4. Plant J 55:89-103

Wang LS, Stoner GD (2008) Anthocyanins and their role in cancer prevention. Cancer Lett 269 (2):281-290 
Table 1 Primers used for cloning and sequencing

\begin{tabular}{|c|c|c|}
\hline Gene & Primer name & Sequence (5'-3') \\
\hline \multirow[t]{2}{*}{ CHS } & $\mathrm{CHScF}$ & ATACATGGCACCTTCCCTTG \\
\hline & CHScR & AGCAGCAACACTGTGAAGGA \\
\hline \multirow[t]{2}{*}{ CHI } & CHIcF2 & TCAACAAAGGCATTTTGAATCTC \\
\hline & CHIcR2 & AGAGTGCTATTCCATTTCTAGCTGAT \\
\hline \multirow[t]{2}{*}{$F 3 H$} & $\mathrm{~F} 3 \mathrm{HcF}$ & GCTTGTGAAGATTGGGGAGT \\
\hline & $\mathrm{F} 3 \mathrm{HcR}$ & GAATTTCCTCAATGGGCTTG \\
\hline \multirow[t]{2}{*}{$F 3^{\prime} H$} & F3' $\mathrm{HcF}$ & AAGGAACAGGGGGATTTGTT \\
\hline & F3'HcR & AAAGTCAGCCCAAATGCTTC \\
\hline \multirow[t]{2}{*}{$F 3^{\prime} 5^{\prime} H$} & F3'5'HcF2 & CATTTTTCAAGAATCTGCCACA \\
\hline & F3'5'HcR2 & GGAACCTCTCGGGAGTGAAC \\
\hline \multirow[t]{2}{*}{$D F R$} & DFRcF & AGAAGGCTGCAATGGAAGAA \\
\hline & DFRcR & GATACGCGAGAGCCTTCAGT \\
\hline \multirow[t]{2}{*}{ ANS } & $\mathrm{ANScF}$ & GTCCAAGGCTATGGAAGCAA \\
\hline & ANScR & TTTGAGCTCAGCAACTGCAT \\
\hline \multirow[t]{2}{*}{ LeEF1 } & $\mathrm{EF} 1 \mathrm{cF}$ & CCAAGAGGCCATCAGACAAG \\
\hline & $\mathrm{EF} 1 \mathrm{cR}$ & ACAAACCAAGGCACCTCAAC \\
\hline
\end{tabular}


Table 2 Primers used in real time RT-PCR

\begin{tabular}{lll}
\hline Gene & Primername & Sequence (5'-3') \\
\hline CHS & LeCHSF1 & AAACTCTTGTCCCCGATAGC \\
& LeCHSR1mod & ACCTAGAGGTTGAAATGCTTC \\
CHI & CHI_TOM_F & GTTTTTCACAAACCAACAGTTCTGAT \\
& CHI_TOM_R & GAAGCAGTGCTCGATTCCATAAT \\
F3H & LeF3HF2 & CATGGATCACTGTTCAGCCCG \\
& LeF3HR2 & TGCTGGATTCTGGAATGTGGC \\
F3'H & LeF3'HF1 & AGGCTTCATCCATCAACACC \\
& LeF3'HR1 & TCAACTTTGGGCTTTTCACC \\
F3'5'H & LeF3'5'HF3 & GCACAACAAGAAATGGACCAAGT \\
& LeF3'5'HR3 & TGGCTCGCTCGATACCCTAG \\
DFR & LeDFRF2 & CATTGAGACTTGCCGACAGA \\
& LeDFRR2 & AGCAGCCATCAAGAACCAAG \\
ANS & LeANSF3 & ATGCCAAGCAGATCAGGAAC \\
& LeANSR3 & TGGGGACATTTGGGGTAGTA \\
LeEF1 & LeEF1F4 & GTTGGTCGTGTTGAAATGG \\
& LeEF1R3 & AACATTGTCACCAGGGAGTG \\
& &
\end{tabular}




\section{Figure Captions}

Fig. 1 Effect of UV-B radiation on phenolic and flavonoid concentration in peel and flesh of tomato fruits of cv. Roma and of the anthocyanin-rich mutant SA206. White and black columns represent control and UV-B-treated fruits, respectively. Data are mean \pm SE of three biological replicates. Different letters correspond to statistically significant differences according to one-way ANOVA followed by Tukey-Kramer post hoc test $(P \leq 0.05)$

Fig. 2 Effect of UV-B radiation on naringenin, quercetin and rutin concentration in peel and flesh of tomato fruits of cv. Roma and SA206. White and black columns represent control and UV-B-treated fruits, respectively. Data are mean \pm SE of three biological replicates. Different letters correspond to statistically significant differences according to one-way ANOVA followed by Tukey-Kramer post hoc test $(P \leq 0.05)$

Fig. 3 Effect of UV-B radiation on expression levels of $C H S, C H I, F 3 H, F 3^{\prime} H$ in peel and flesh of tomato fruits of cv. Roma and SA206. White and black columns represent control and UV-B-treated fruits, respectively. The transcript amount in the flesh of cv Roma under UV-B treatment was arbitrarily set to 1 and served as calibrator for relative expression levels in each transcript. Data are mean \pm SE of three biological replicates. Different letters correspond to statistically significant differences according to one-way ANOVA followed by Tukey-Kramer post hoc test $(P \leq 0.05)$

Fig. 4 Fruits of cv. Roma (a) and SA2O6 (b). Purple spots due to the Aft allele are evident on the surface of SA206 fruits

Fig. 5 Effect of UV-B radiation on delphinidin, petunidin and malvidin concentration and expression levels of $F 3^{\prime} 5^{\prime} H, D R F$ and ANS in the peel of tomato fruits of SA206 mutant. The 
transcript amount in the peel of SA206 under control conditions was arbitrarily set to 1 and it served as calibrator for relative expression levels in each transcript. White and black columns represent control and UV-B-treated fruits, respectively. Data are mean \pm SE of three biological replicates. Different letters correspond to statistically significant differences according to one-way ANOVA followed by Tukey-Kramer post hoc test $(P \leq 0.05)$

Fig. 6 Effect of UV-B radiation on phenolic, flavonoid naringenin, quercetin and rutin concentration and expression levels of $\mathrm{CHS}, \mathrm{CHI}, \mathrm{F3H}, \mathrm{F3}{ }^{\prime} \mathrm{H}$ in peel and flesh of tomato fruits of mutant $h p-1$. The transcript amount in the peel of $h p-1$ under UV-B treatment was arbitrarily set to 1 and served as calibrator for relative expression levels in each transcript. White and black columns represent control and UV-B-treated fruits, respectively. Data are mean \pm SE of three biological replicates. Different letters correspond to statistically significant differences according to one-way ANOVA followed by Tukey-Kramer post hoc test $(P \leq 0.05)$ 
Figure 4

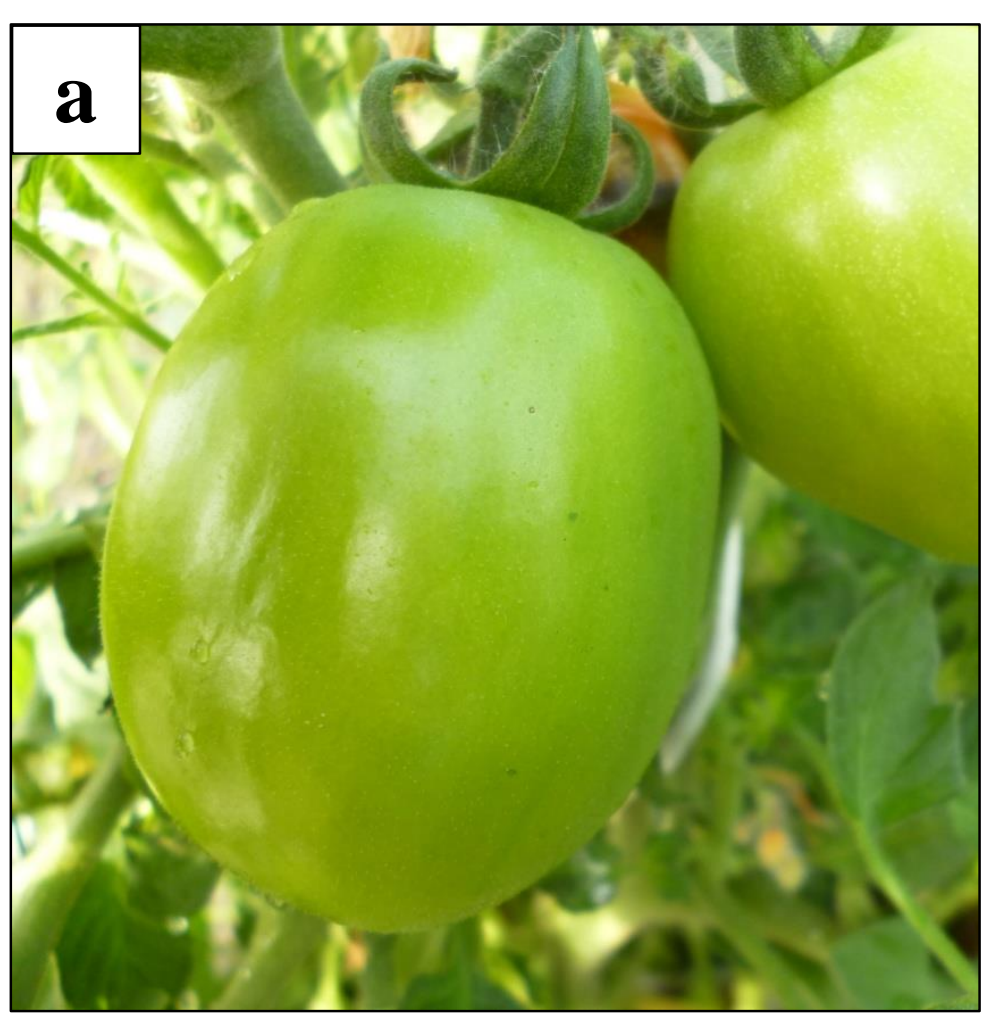

cv. Roma

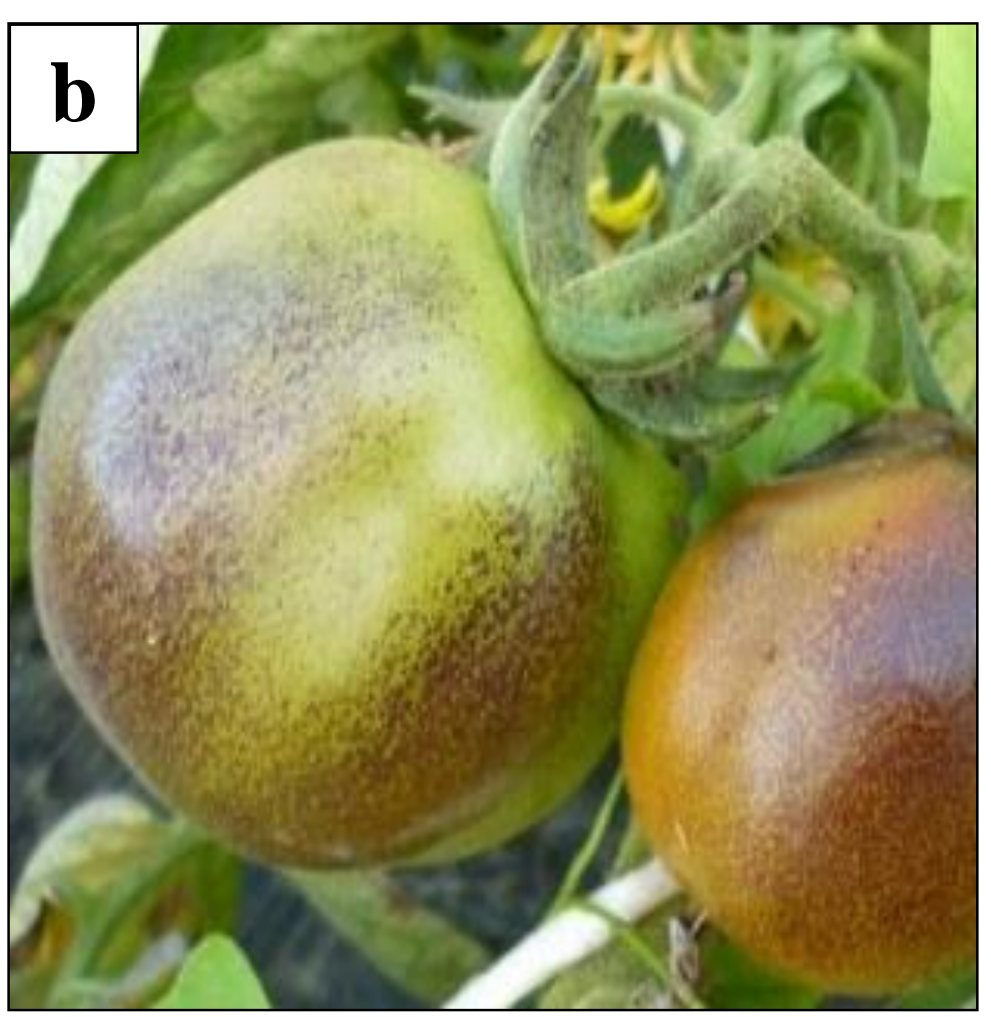

SA206 (Aft hp-1) 
Figure 5

SA206

PEEL
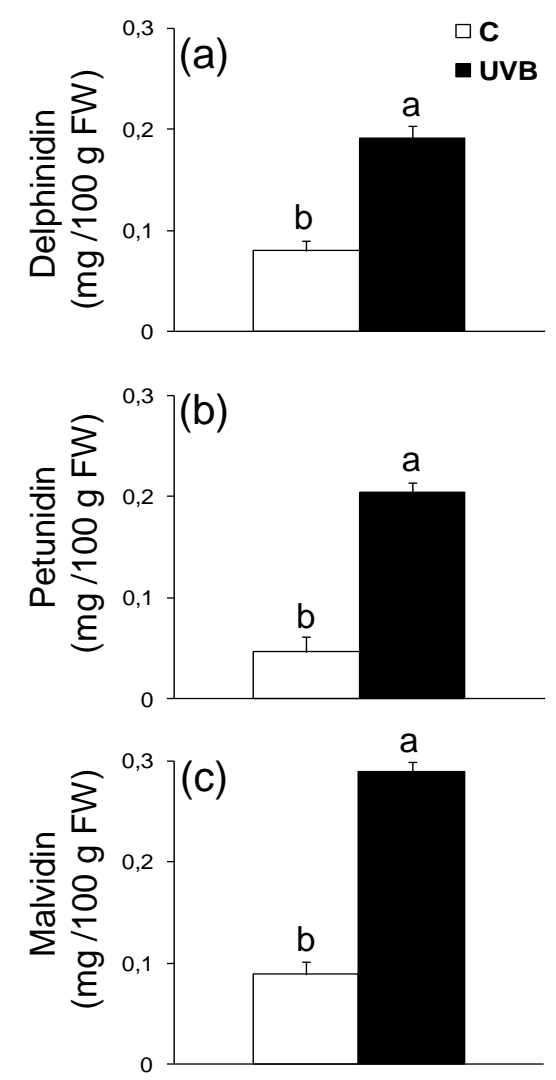

SA206

PEEL
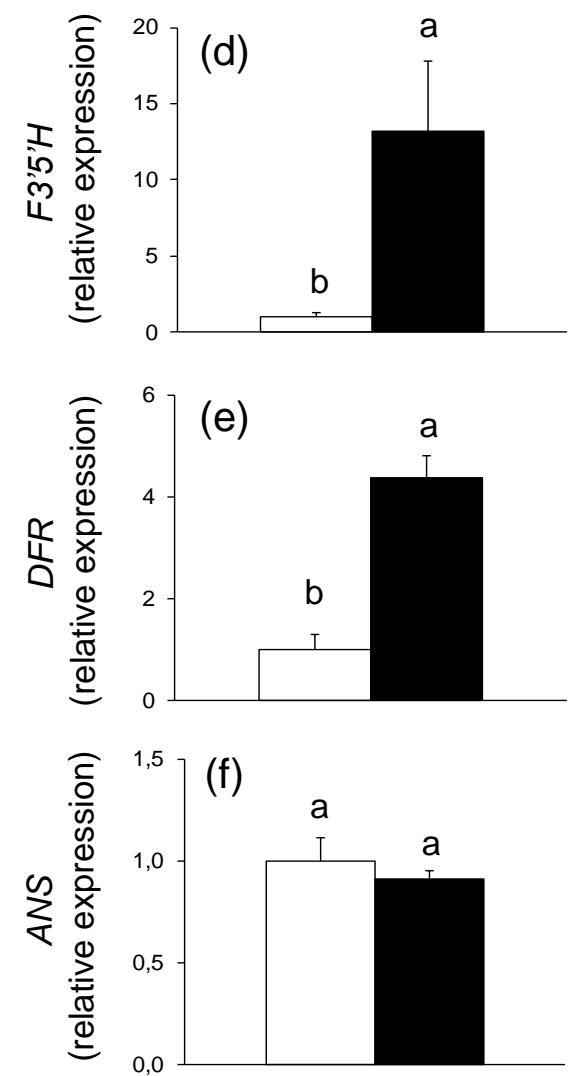

Fig. 5 
Click here to access/download

\section{Supplementary Material fig S1.pptx}

